\title{
Organizational remembering as a trigger for cultural change: Exploring the episodic memories of a financial scandal.
}

\author{
Lucia Garcia-Lorenzo \\ Psychological and Behavioural Science Department \\ London School of Economics \\ 1.garcia@1se.ac.uk
}

\begin{abstract}
Organizational memory research has developed from the 'storage bin' model of memory towards emphasizing collective remembering. I advance this view by proposing organizational remembering not just as the process of evoking past events to reproduce traditions but also as a projection into the future using imagination. Empirically this is illustrated through the qualitative analysis of 27 episodic interviews with employees of a global financial institution, documents and the media coverage of the organization's involvement in two well-publicized financial scandals. We explore the impact of the episodic memories of those events on employees' readiness for the cultural change programme launched by management after the scandals. The analysis shows how the negative media coverage of the organization generated a powerful dis-confirmation of its working practices among employees and how this was amplified by the strong emotional reactions remembering those events provoked. Management used both to re-frame the past in a narrative used to increase receptiveness to change. Yet the past was brought differently into the present by different organizational groups depending on the future each group imagined, counteracting the impact of the generic management narrative. The findings illustrate the collective, emotional and imaginative qualities of organizational remembering and provide new insights into the process of cultural change through the lens of memory showing how while memories may be shaped by management to respond to crisis, they can also become part of prospective and transformative change processes.
\end{abstract}

Key words: organizational memory, memory making, collective remembering, cultural change, organizational change, financial institutions, narratives.

\section{Introduction}

The 2008 global economic crisis and subsequent financial scandals damaged confidence in the banking industry at all levels of society. After reports like the Kay and Salz Reviews in the UK a consensus emerged that a negative bank culture was a core cause of the crisis and the root-cause of bankers' poor behaviour (Parliamentary Commission on Banking Standards, 2013a). Following these reports a sustained campaign led by the media and other stakeholders for banks to profoundly change their culture ensued internationally (Silverman, 2013; Turcke, 2015). The stated aim of 
those political and media campaigns was not just to achieve a cosmetic makeover to restore reputations, but a demand for fundamental change to support 'ethical long-term value creation' (e.g. House of Lords, 2013). Yet in the current context of an improving economy and customer inertia to change banks, sceptics argue that the extent of reform has been limited and that it 'will take a generation' of bankers to forget the past in order to achieve any real change (REF).

Breaking with a problematic past has been attempted by many financial organizations introducing cultural change programs to modify perceived unethical practices and behaviours (Turner, 2009). This paper looks at one of those cases exploring how the collective recollection of episodic events such as the economic crisis and two well publicized financial scandals involving the FX Group (FXG) - a global financial institution headquartered in the UK- impacted on the receptiveness to a cultural change programme among different groups within the organization. The research was designed as a longitudinal qualitative case study focusing on episodic memories, the subjective recollections of an event transmitted in the form of stories (Schachter, 2001). We draw on 27 in-depth episodic interviews at FXG, organizational documents and on the media coverage of the institution from 2008 to 2014. In 2012 FXG embarked on a global-wide cultural change programme in the wake of the financial scandals with the goal of becoming the bank of choice for its stakeholders. At the time of this research, the organisation was 18 months into this programme.

Traditionally organizational memory studies have focused on how the past can be retrieved to bear on current decisions in a useful manner (Walsh \& Ungson, 1991). However social memory scholars have recently criticised this approach by arguing that memory cannot be controlled for managerial purposes (Anteby \& Molnar, 2012) as it is collectively reconstructed as well as historically, socially and culturally situated (Casey \& Olivera, 2011). In this paper we extend this approach proposing organizational remembering as a process that engages with memories of the past not only as evocation to reproduce traditions but also as possibilities to be actualized or 
rejected in the present in view of future aspirations. This has an impact on the receptiveness and commitment of employees to planned cultural change programs in organizations.

Our analysis of the FXG data shows that while the financial crisis led to intense reflection and learning in the organisation, it was external pressure after the financial scandals that triggered emotional sensemaking among employees and a 'will-to-cleanse' by the management team. Perceived unethical practices and behaviours within the system were targeted and a new valuesbased culture was engineered and disseminated across the organization through 'The FXG story', a narrative constructed after the scandals about the past, present and future aspirations of FXG. Employees were encouraged to accept cultural changes by a combination of media and management disconfirmation -constant reminders of how their working practices were 'suspect'-, as well as emotional arguments - e.g. need to put a 'shameful past' (Olick \& Levy, 2007) behind them to restore pride-. Yet the possibilities of the past were brought differently into the present by various groups in the organization depending on the future each group imagined, counteracting the generic management narrative. Our results illustrate empirically how organizational remembering is indeed a collective process where multiple voices contribute to weave organizational memories and where both imagination and memory point in different directions, serve different functions, and operate beyond concerns with desired or even truthfulness of perspectives. The result of this polyphony were relevant group recollections that both facilitated receptiveness to the cultural change program as well as provided arguments to resist it (McCabe, 2010).

The paper is organised as follows: the first section reviews the literature on cultural change and organizational remembering. The second section focuses on the research design and methodology for data collection and analysis. Section three presents the findings of the qualitative data analysis in the form of a narrative while the final section discusses the main insights from the case study linking them to relevant literature. 


\subsection{Cultural change and memory in organizations.}

Interest in cultural change in organizations started in earnest in the 1980s (Martin, 2002) and has continued unabated until now. Researchers have looked for better ways to understand and/or accomplish cultural change either through direct purposeful interventions to achieve strong (Sørensen, 2002), ethical (Nwachukwu \& Vitell, 1997) or efficient cultures (Bate, 1995) or indirectly through the understanding of how cultural phenomena such as narratives (GarciaLorenzo, 2010; Humphreys \& Brown, 2002; Ravasi \& Schultz, 2006), basic assumptions (Schein, 1996), working practices (Alavi, Kayworth \& Leidner, 2005) or identities (Parker, 2000) change in organizations over time. A particularly popular quest has been to find the factors influencing receptiveness to cultural change, especially in relation to resisting any change effort (Bartunek, 2006). The result is an abundance of multi-staged cultural change models all purporting that different interventions are required at different times in order for employees to embrace change and remain motivated throughout the process (Kotter, 1996).

Most of the current organizational cultural change models share the assumptions made by Kurt Lewin's three-stage model of organisational change - unfreezing, changing and re-freezing (Burke, 1994; Lewin, 1951/1997) where 'unfreezing' is seen as the necessary step of breaking with the past to unlearn (Argyris \& Schon, 1978) or reframe a complex schema of understandings, beliefs and values in order to change behaviour. Due to its focus on group involvement and trialand-error testing, planned cultural change initiatives are often criticized as slow, static and only suitable for times of stability, not dynamic interrelatedness and complexity (Dawson, 1994; Hatch \& Cunliffe, 2006; Kanter, 1999). The alternative are emergent change models which describe cultural change as unpredictable, often unintentional, coming from anywhere, and involving relatively informal self-organising (Weick \& Quinn, 1999). The idea of change as continuous (Chia, 1999; Tsoukas \& Chia 2002; Weick \& Quinn, 1999) is becoming more prevalent and yet 
change is still often experienced by organizational members as disruptive, related to resistance, loss of security and fear of uncertainty and therefore in need of being managed.

The underlying assumption in current cultural change theories is that if organizational culture is a social construction, it can be changed and shifted in a new direction by management. Certain circumstances like a crisis can facilitate unlearning (Martin, 1985), yet 'inertia' - the result of deep rooted cultural practices and routines that have evolved and been co-created over years, is seen as engendering resistance to new ideas and practices (Stein, 1995). Thus, the way we understand and recall the past to reframe the present is also considered a potential barrier to change with long-tenured employees often seen as guardians of the status quo, unwilling or unable to change (McCabe, 2010).

A number of understandings come together to inform the narrative where breaking with the past is seen as the necessary step to 'real' cultural change. First, changing organizational culture is seen as achieved by intention "inertial, linear, progressive, goal seeking, motivated by disequilibrium, and requir[ing] outsider intervention" (Weick \& Quinn, 1999, p. 366). Second, it is also seen as dramatic. According to Lewin (1951/1997, p.120) one needs emotional stir-ups "to break open the shell of complacency and self-righteousness" and bring about cultural change. Strong emotions are also seen as bringing 'major sources of energy for revolutionary change' (Gersick, 1991). And third, memories of the past are seen as finished stored products that can be retrieved, reframed and latter refreezed in a way that supports "new habits [becoming] possible" (Schein, 1993, p. 89). This approach to cultural change in organizations resonates with the inputoutput model put forward by Walsh and Ungson (1991, p. 61) in their seminal study describing how organizational memory as "stored information [] can be brought to bear on present decisions" in a useful manner.

Walsh and Ungson (1991) argued that experiences and interpretations of the past are retained 
in 'storage bins' - individuals, culture, transformations, structures and ecology which can be useful for the future. At the aggregate level of analysis (culture), collective memory was seen as retrieved through schemata (Bartlett, 1956) to aid problem solving after an organisational crisis. The understanding was that the proper use of memories can be useful in reaching higher levels of organisational effectiveness giving the organization a competitive advantage (Stein, 1995). This functionalist view of memory prompted research in a number of areas connected to organisational cognition aiming at making the process of organising more efficient. This includes research on decision-making (Berthon, Pitt \& Ewing; 2001), behaviour (Weick, Sutcliffe \& Obstfeld; 2005), learning (Argyris \& Schon, 1978), knowledge (Nag \& Gioia, 2012) technology (Ackerman, 1998) and innovation and creativity (Moorman \& Miner, 1997).

The functionalist approach to organizational memory has received however extensive criticism from social theorists who have vociferously argued that memory cannot be controlled for managerial purposes (Anteby \& Molnar, 2012). The main criticism has been against an understanding of organizational memory as an entity, separated from its context and eventually stripped from all the human elements of 'remembering' - emotions, identity, history and culture (Feldman \& Feldman, 2006). Thus, the meaning of memory for organisational members has been ignored in the pursuit of developing theories to enhance organisational performance.

An alternative conceptualization sees organizational memories as collectively reconstructed as well as historically, socially and culturally situated (Casey \& Olivera, 2011; Rowlinson, 2010) implicitly recognizing their unfinished and processual nature. In doing so researchers have moved from understanding organizational memory as mechanical retrieving to emphasize organizational remembering as an ongoing process. We advance this view by looking at collective remembering in organizations not only as a retrospective exercise where memory evocation is directed exclusively towards reconstructing the past but also as 'memory making' by different organizational groups 
through "prospective activit[ies] oriented towards the future" (Hernes 2014, p. 121). We develop this perspective and explore its implications for cultural change in organizations in the next section.

\subsection{Organizational remembering as memory making.}

Organizational remembering is a proactive social and cultural process. Already Halbwachs $(1925 / 1992)$ in his classical work "On Collective Memory" argued that individual memory is only possible through participation in social life. Social groups offer culturally legitimate frameworks to individuals to aid their recall of the past. But these frameworks are collectively formed by social interactions and shared language in which remembering involves "an effort after meaning" (Bartlett, 1956). Individual remembering occurs indeed in relation to these pre-existing sociocultural frameworks. Yet, as Wertsch (1997) argued memory is done in a group, not by a group. This socio-cultural elaboration on remembering links collective memory to group an active construction of identity for "we can't know who we are if we don't know where we have been" (Wertsch, 1997:5). He also argues that collective memory is constructed using culturally developed narratives (Wertsch, 2009). These become frameworks for recalling the past but are elaborated upon in the present.

The implication is therefore that organizational memories are formed largely in the present from the perspective of contemporary and future interests. This 'entrepreneurial' perspective (Olick, Vinitzky-Seroussi \& Levy, 2011: p. 42) on organizational memory 'making' emphasizes how images of the past can be distorted, deployed for instrumental purposes and used to propagate particular narratives. Yet, the process of memory making is more than "cynical muckraking" (Schwartz, 2003, p: 11) to "invent [] traditions" (Hobsbawm \& Ranger, 1983). Collective remembering -linking past, present and future- is a central faculty of being in time through which we define individual and collective identities. It is also a way of imagining the future. And as research has shown, 
prospection - the representation of possible futures is a ubiquitous feature of the human mind (Gilbert \& Wilson, 2007) as well as a central organizing feature of memory and action (Seligman, Railton, Baumeister \& Sripada, 2013).

Memory making is also a political process. Conceptualizing organizational remembering as a dynamic process implies that certain individuals or groups might become more powerful than others in articulating their version of the past. For example, who becomes identified as either the perpetrator or the victim of the financial crisis depends on who is narrating the past and on their objectives for the future (Davies, 2010). This is because different cultural groups, in unique social positions, often vie with one another about legitimate ways of interpreting that past.

All this makes remembering a very emotional act. Indeed, the process of collectively remembering past events is coloured by emotions shared through narratives and stories (Boje, 1991; Akgun \& Keskin, 2012). Yet, a critical review of the literature shows that employee emotions tend to be either downplayed (Bartunek, 2006) or framed through a negative concept of resistance (Kuhn \& Corman, 2003). This has led to conceptually under-developed discussions and a call for further research on the role of emotions in organizational remembering (Rowlinson, 2010). Emotion is not just a by-product of, or a trigger to change processes, but an integral component of any cultural change (George \& Jones, 2001).

In contrast with a view of memories as locked in containers and belonging to the past, basically separating past, present and future as discrete periods of time (Walsh \& Ungson, 1991); we want to emphasize a processual view of memory where both past and future are an integral part of present recollections. Thus, collective remembering cannot be seen exclusively as a retrospective process neither does memory belong exclusively to the past since everything that is and will be, has a 'pastness' (Shotter, 1990). Understanding organizational remembering as both a retentional and a prospective process invites a particular direction to the analysis of organizational recollections and 
their implications for the design and implementation of cultural change programs in organizations. We illustrate this process below.

\section{Methodology}

The paper addresses how the collective recollection of episodic events such as the economic crisis and two well publicized financial scandals involving the FX Group (FXG) - a global financial institution headquartered in the UK- impacted on the receptiveness to a cultural change programme among different groups within the organization. In order to do so, we designed our research as a qualitative case study involving episodic narrative interviews and text documents on the basis that communication, stories and narratives are vehicles for reconstructing our past and making sense of the events that affect us in light of our present and future expectations (Halbwachs, 1992; Weick et al, 2005). As Schuman writes collective remembering through storytelling brings about the widely shared images and knowledge of a past social event even if that event has not been personally experienced. Through the sharing of stories an event becomes collectively recreated, reshaped and shared endowing it with particular social functions (Schuman \& Scott, 1989). Collecting and analysing organizational narratives allowed us therefore to investigate how the events from the past are recollected in FXG (Adorisio, 2014) incorporating both the contextual and experiential nature of remembering (Rowlinson, Hassard, \& Decker, 2014).

\subsection{Research Context}

FX Group (FXG) employs 140,000 people worldwide and comprises a number of subgroups, three of which are the focus of this research- the investment bank, the retail bank and wealth \& investment management. Historically, these sub-groups have operated autonomously with their own management teams and were considered by participants to have distinctive tasks, cultures and identities. During the research process it became clear that each sub-group had its own 
distinctive recollection of the episodic events being investigated and their own imagined futures, yet there were also shared recollections across all sub-groups.

In the summer of 2012, FXG was in the media spotlight after they publicly admitted that they had rigged the London Interbank Offered Rate (Libor). This provoked the departure of the Chairman, the Group CEO and other board-level allies in quick succession. The CEO of the retail bank took the helm as new Group CEO although a previous financial scandal regarding payment protection insurance (PPI) mis-selling had taken place under his watch. The organization's culture was perceived to be the root-cause of misbehaviour in the bank (internally and externally) shaped by the former Group CEO's 'growth-at-all-costs' strategy. This provoked a period of organisational reflexivity (Schultz, Hatch \& Larsen, 2000) that lead to the deployment of a cultural change programme.

A new values-based organisational cultural framework (NVF) was engineered to achieve a number of objectives (1) integrate a disaggregated organisation (2) restore trust and its reputation, (3) mitigate individual risk-taking (4) create relevance for the future and (5) propel performance. Work on the first objective had already commenced in 2011 by the former Group CEO when he created 'One FX Group' thereby discarding the name of the well-known and highly respected investment bank. The cultural change program aimed to develop a single set of values for the organisation and for the new management team to integrate into their own working processes. At the time of this research, the organisation was 18 months into this change programme.

Every employee attended a half-day values workshop to learn about the values and understand their implications for day-to-day working practices and behaviours. Approximately 1,500 'values leaders' were assigned to support the embedding of the new values. To help employees engage and support the need for change, 'The FXG Story' was created reframing the past while trying to articulate a new future (Schultz \& Hernes, 2013). While access to all internal 
documents was not granted due to their confidential nature, participants describe 'The FXG Story' in their interviews in relatively clear detail. 'The Story' focused on the past (the proud history), present (how the world has changed) and future (aspirations) and was used by management as a tool to shape new narratives about the organization. Important symbolic changes were also made in the form of displaying the new mission and values in reception areas, meeting rooms and in internal documentation. Yet late in 2013 doubts persisted that despite a good reception of the new values particular 'resistant' recollections of the financial scandals were hindering 'organizational change readiness'. This was the starting point of our research.

\subsection{Data generation}

Participants in our research were drawn from various job levels in the banking hierarchy from non-managers with operational responsibilities to managing directors with a more strategic perspective. Representation across sub-groups was also sought to see if distinctive collective recollections existed at the aggregate level. It was also essential that employees had 'lived' through the financial crisis so long-tenure (pre 2008) was the third criterion. Participants had an average job tenure of 11.5 years with the longest serving employee being in the bank for 35 years and the shortest for 4 years. Access to participants was facilitated by HR, but after the first few introductions snowballing was used to identify further participants.

Face-to-face episodic interviews were conducted with 27 participants ( 6 from the Investment bank, 9 from Wealth Management, 10 from the Retail bank and 2 HR managers) between 2013 and May 2014 at their workplace. The purpose of the episodic narrative interviews was to ask participants to remember past events and recall them in narrative form (Flick, 1998, p.186). The majority of interviews were conducted at FXG's global headquarters in Canary Wharf, London but also in retail branches located in towns across the South East and South West of England including the Isle of Wight. Interviews lasted fifty minutes on average. Interviewees were asked about 
themselves and the organization, their memories and reactions to the 2008 financial crisis and its personal impact as well as about major organisational changes they had seen since the crisis, a description of the organisation today (comparing past and present) and their concerns about the future. Contextual information about each interview was recorded afterwards.

Organizational documents pertaining to the organizational responses to both the crisis and the financial scandal as well as to the launch and implementation of the cultural change program were also collected. Furthermore, a selection of U.K. media coverage of FXG between 2008 and 2014 was also conducted after the interviews revealed the impact of the UK media on employees' recollections. The search for media articles covering the organization's performance from 2008 to 2014 yielded a total of 757 focused results. We selected only those media articles that explicitly mentioned both the crisis and the scandals as well as their impact on the organization's financial performance. A final group of 10 articles was selected to be fully integrated in the text analysis. The final media articles selected were both directly cited by participants as a referential narrative in their interviews and they address directly a key topic that emerged during both the interviews and the text analysis. Those articles were also selected on the basis of specific events that had placed FXG in the media spotlight and provoked an emotional response among participants.

\subsection{Data Analysis}

The interview data was analysed thematically and followed coding procedures recommended by Gioia, Corley and Hamilton (2013) and Braun and Clark (2006). Interviews were audio-recorded and transcribed verbatim. Interview transcripts were printed and re-read multiple times and discussed between two researchers before analysing them with Nvivo software. A deductive (data driven) coding framework was created. The first step was to use NVivo to code the text into bottom up first order codes which were subsequently clustered together around second 
order codes bringing together data and theory. First order codes referred for example to memories of the crisis and the two scandals, reactions such as fear, shame and anger at the media coverage of the organization as well as individual reactions to the proposed cultural change programme. Those first order codes were latter clustered around second order themes looking at the images of the crisis, the public opinion on the organization and scandals, the memories facilitating change and those used to resist change etc. At this point in time it was clear that although common themes such as the need to change ethical behaviours or concerns about the appointment of a new CEO were shared across the bank, different groups brought those memories up differently. A final stage in the analysis included to look for differences between and within sub-groups. In the final stage we reviewing the codes from a theoretical, 'inductive' standpoint to ensure all concepts had been captured (Boyatzis, 1998). This hybrid approach (Fereday \& Muir-Cochran, 2006) enabled us to organise the results at both sub-group and organisational level.

The media articles were downloaded, read in search of common themes and finally classified according to the following themes: coverage of financial activities by FXG, responses to the crisis and/or the scandal, public opinions in regard to the organization as well as generic understanding of the scandal and the crisis in relation to FXG. A final crop of the most complete 10 media articles in regard to our coding categories were selected to be fully integrated as texts into the overall thematic and narrative analysis.

\section{The collective remembering of financial events at FX Group}

This section focuses on the narrative of the crisis, the role FXG played in the financial scandal and the subsequent cultural change program launched by management as told by the employees. The narrative is structured by the main events that employees cited as the triggers for the deployment of the cultural change programme and their agreement or rejection of that change 
programme. Table 1 illustrates the main narratives and themes.

Table 1 about here.

\subsection{Evocation: The triggers for reflection and cultural change}

\subsubsection{Financial crisis 2008: "It was not us".}

On $16^{\text {th }}$ September 2008, Lehman Brothers collapsed triggering a global financial crisis (BBC, 2009). Comparing previous responses by the FXG to other economic crisis, employees unanimously described the 2008 financial crisis as 'different', as a 'rollercoaster of emotions'. The responses to this 'rollercoaster' ranged from 'being stimulated by the drama' to a 'Dunkirk spirit' to get things sorted, to feeling anxious, uncertain, fearful and vulnerable about the survival of FXG and overall finance capitalism (Holland, 2010).

"The hardest part of it I think was simply not knowing whether tomorrow you'd be the next institution that went bang. There was talk in the market of it for a while which obviously destabilises you.... at the time the crisis happened I'd been in the industry over 20 years, I'd been through the crash of ' 87 and all the crises in the nineties...but this one definitely did seem different ...it could actually blow the whole thing to pieces." Director, Wealth

Employees were asked to recall how FXG reacted during the financial crisis and it was the strong, communicative and calming influence of senior leadership that was remembered - the organisation had a strong history and 'they would be fine'. This is not only "'The FXG story' effect" of presenting the organization as 'strong in the face of danger'; in the retail bank, employees remember increasing their customer base as FXG was perceived to be a safer bank:

"I just remember customers coming in with just cheques to pay in - into savings accounts because they felt their money wasn't safe with other institutions...unprecedented...we probably doubled what we were taking in...it kind of doubled, trebled overnight. It was just ridiculous." Regional manager, retail bank

Amidst a negative spiral of declining confidence that led to inter-bank market freezes, bank failures and government bailouts (Holland, 2010, p. 94) the senior leadership's ability to navigate FXG through the crisis and avoid a government bailout is remembered as a source of immense pride 
among employees. The bank had survived and it provoked feelings of 'we're not part of this'. Furthermore, FXG benefited from the financial crisis by purchasing functions of failing banks to bolster their own capabilities. The acquisition of parts of one particular bank catapulted FXG onto the global stage and activities relating to integration and expansion quickly pushed discussions about the financial crisis into the background. While the crisis had not been forgotten; the then present set of events were occupying all employees' time and focus (Vaara, 2003).

\subsubsection{Lessons from the crisis}

The recollected memories of the crisis revealed a focus on 'intense learning' (Holland, 2010), driven by waves of enforced regulation which were now embedded in working practices and routines, recruitment (e.g. more procedural types of people were being hired to thrive in the "new environment'), organisational structures and decision-making (Walsh \& Ungson, 1991). Yet the pendulum was perceived to have swung too far in the wrong direction and regulation while 'maybe necessary' was making it harder to do business and stifling creativity. It forced employees to think differently for the 'right reasons' but a number of employees felt that it inhibited personal responsibility and accountability - some employees were 'too scared' to make decisions in case they made a mistake, which was slowing down the pace of work.

"The biggest change has been the processes and the regulations put in place when you do business... Nowadays, ever decision, every client, every client interaction....anything you do, even what you do sometimes in your personal life, is subject to a variety of checks...The pendulum has swung from the bank being very relaxed about regulation... to like...I think sometimes we go overboard. " Managing director, Investment bank

\subsubsection{2 and 2013 Financial Scandals: "We need to re-set".}

After the financial crisis two major, industry-wide scandals followed in its wake - the rigging of the London Interbank Offered Rate (LIBOR) in the investment bank in 2012 widely covered in the press and the mis-selling of Payment Protection Insurance (PPI) in the retail bank in 2013. According to employees, they related to legacy issues traced back in their narratives to the 
boom years (pre 2008) of expansion, optimism and ego - an environment remembered as 'growthat-any-cost'. In their collective recollections, an outcome of this strategy was a culture that had shaped itself and was perceived to have been the root-cause of mis-behaviour (Salz, 2013). These scandals served to perpetuate the public's perception that banks had made no attempts to implement genuine change in their organisations since the financial crisis.

According to the shared accounts, the impact of the Libor scandal posed more of a threat to FXG's survival than the financial crisis. Employees remembered feeling a mix of emotions of shock, shame (Creed, Hudson, Okhuysen \& Smith-Crowe, 2014) embarrassment, anger, disgust and contempt (Hutcherson \& Gross, 2011) on hearing the news of unethical practices within their own organisation.

"I just remember LIBOR and thinking I've never been this embarrassed about working for an organisation and I felt really bad because, you know, whilst customers are saying it to you, after a while it's sort of: "yeah I know"...you can only put up so much of a defence can't you ?" Regional manager, retail bank

The coverage of the financial scandal by the press is remembered as triggering a sense of disconfirmation (Schein, 1993), where FX employees started to question if "their current ways of doing things were no longer working". This destabilised personal identities (Weick et al, 2005) and triggered an urgent 'will-to-change' (Cooper, 1986) to restore pride, reputations and positive personal identities. Yet, according to employees' shared recollections while the Libor scandal was the catalyst to design a cultural change programme because it was seen as 'personally relevant' (George \& Jones, 2001) it cannot be viewed in isolation from other episodic events (i.e. financial crisis or PPI). Societal pressure for banks to change their culture had been mounting over the last six years which enhanced the 'urgent' need to change.

"There's...a number of different triggers... what happened in July 2012 gave the organisation the opportunity to take a look at itself and ask itself 'what's the point in all of this? What is our overarching purpose here... so I think that external 'we need to re-set what banking is all about' was a very important change." Managing director, Group HR 


\subsection{Bonfire of the Bankers ${ }^{1}$}

To add to the internal pressure, the UK media coverage of the scandals is remembered as having a clear impact on morale and understandings of personal work identities. It is widely acknowledged that the media are influential sensemakers and sensegivers in their practices of framing a particular reality to their audience (Risberg, Tienari \& Vaara, 2003 p. 134) and how coverage about organisations in critical situations can negatively impact employees (Korn \& Einwiller, 2013). Over the last six years the UK media has played a pivotal role in reframing the public's memory of the financial crisis acting as 'crisis intensifiers' (Korn \& Einwiller, 2013 p. 451) and driving a campaign for change by recollecting the financial crisis in particular ways, mainly through 'shaming attempts' (Creed et al, 2014). In the shared accounts FXG employees gave during this research, two main themes emerged - the impact of (1) sustained 'banker bashing' and (2) targeted attacks on FXG.

\subsubsection{Banker bashing: Not all bankers are the same.}

An analysis of UK media coverage between 2008 and 2014 reveals a recurring metaphor of investment bankers as 'criminal gangsters' and 'gamblers' which played a critical role in the reconstruction of banker identities at FXG. This kind of imagery regarding bankers is not new and has in fact endured over time (Albert \& Whetten, 1985) evoking antithetic emotions of both contempt and respect among the public. The reproduction of these stereotypes in the UK media intensified after the financial crisis and PPI and LIBOR scandals provoking very strong emotional responses of anger, unfairness and helplessness among financial sector employees (Korn \& Einwiller, 2013) who considered themselves to be 'ordinary workers' in banks and did not

$1 \quad$ The headline originates from the book 'Bonfire of the Vanities' written by former investment banker Tom Wolfe in 1987. The reproduction of this headline was frequently used by the UK press after banks announced mass redundancies to symbolise the cleansing of an unethical past - see the Telegraph (7 August 2011), Independent (16 Oct $2011)$ the Economist ( $\left.4^{\mathrm{t}} \mathrm{Feb}, 2012\right)$ and the Evening Standard ( $8^{\text {th }}$ May, 2014). 
appreciate being tainted with the same brush. FXG employees were not different. The recollections of those attacks still generates strong rejection and reaffirmations of particular personal identities:

"I will correct people quite often about who are you calling a banker? Because I work for a bank? And I am proud of it. But I don't associate myself with people that destroyed the economy." Regional manager, retail bank

"If I read another article about bankers I might as well give up, because I'm not- you see, to me, I'm not a banker ... I work at a bank." Director, investment bank

FXG employees report strong disassociations with the media portrayals and reframing of 'bankers', yet many recollections were shared about those clichéd moments at dinner parties when they felt ashamed and were unable to be honest or explain their profession to others. This was especially the case among retail banking employees. An interesting exception was among investment bankers themselves who adopted a more phlegmatic attitude, seeing 'banker bashing' as par for the course and 'less subject to change' (Risberg et al, 2003). As one investment banking employee put it 'we have always been misunderstood'.

The dynamic between sub-groups was complex as negative media coverage aimed at one part of the bank would impact other areas creating tensions and reinforcing historical 'us and them' discourses. For example, employees in the retail bank remembered how the impact of media coverage of the bonus culture in the investment bank affected their daily work:

"There were stories floating around of some customers getting annoyed and aggravated with our cashiers and moaning at them about enormous bonuses despite the fact that cashiers don't get any bonus and that they're on a tiny salary" Branch manager, retail bank

However there were positive recollections across all sub-groups of customers being able to distinguish different individuals from the picture the overall organisation and/or wider banking industry was being given by the press and the Government reports:

"I remember we had customers at the peak of all the media coverage, you know, the fat cat bankers and all that, and we had customers bringing in boxes of chocolates and stuff for our 
staff in the branches...because it's: 'I know you care about me and my business and I value what you do for me, you know, it's your bosses that I don't trust or other people.'... so there is a separation out between the person I interact with day-to-day in my banking and those people running that bank." Director, retail bank

\subsubsection{Personal attacks on FX Group: We were never given a fair trial.}

The vast majority of employees felt that the media was right to scrutinise FX Group for poor behaviour, yet they felt pilloried because their organisation had been singled out by the press when in fact misbehaviour was industry-wide. The comments of a managing director in the investment bank illustrate this view:

"Other financial institutions performed as badly if not worse and there were problems with other organisations, but it's just [FX Group] as a name. Or maybe it's the UK press which ...picks up a person and just beats them to death." Managing director, investment bank

This served to heighten employees' awareness that the external image of banks (and their own organisation) had changed which led to acute sensitivity of how organisational behaviour could be perceived by the public. One such example that was remembered across all sub-groups was the Daily Mirror's coverage of a senior leader at the races in the wake of Libor which was described by many as an 'insult' (Smith, 2013), and being generally recollected with embarrassment (Hutchinson \& Gross, 2011):

"We've seen people go...you know, the mad senior exec that was at Ascott with his Fat Cat....I mean that was shocking. So he was one of our top people who was on the front page of the Metro with his - he's got a race horse, and it was [called] Fat Cat in a Hat.....and you're having to talk to your people about well, you know, it's been taken out of context but basically you're thinking 'prat' you're not helping. Seriously. It does not get more embarrassing. He went quite quickly after that and that's a good thing. So I can call him a prat now." Regional manager, retail bank.

In a similar vein, and to counteract both the media portrayals and underlying 'The FX story" effect; the majority of employees interviewed shared recollections of their personal involvement in 
the community at the time, reinforcing the message that they were 'good' people. Yet FXG was not prepared to advertise these philanthropic activities externally, particularly after Libor when even physical safety was perceived to be at risk.

"I remember I did a London 10k just shortly after the LIBOR scandal...it was actually on the weekend and [FX Group] matched me pound for pound and that money went up to the Make A Wish Foundation... On the Friday before the run... internal communications emailed us and said do not wear [FX Group] branded T-shirts. Wear your own T-shirts. Because they were scared of the brand, you know, us doing things out in the market. Might get physically dangerous for us. So we do a lot but we under-sell ourselves because we have to be humble now." Assistant Vice President, Wealth

Internally however the bank reframed the scandal episodes differently. A number of employees in FX Group's head office recalled how their internal marketing department promoted 'feel good' stories to raise morale. While the goal may have been to stabilise the organisation (Korn \& Einwiller, 2013), communication of this nature served to further frustrate employees:

"...the level of internal propaganda cranked up alarmingly...the Ministry of Truth...blurted on the TVs at 12 o'clock for an hour every day with... what we're doing well and little good luck stories ...you can preach to children like this, but...it was just becoming irritating especially while they were making lots of people redundant." Vice president, Wealth

The media's 'shaming attempts' (Creed et al, 2014) while having a detrimental impact on employees' morale were also used by management to enhance receptiveness to the organisational changes that were about to be implemented. The 'shameful past' became reframed as a case of 'adapt or die'.

\subsection{Memory making: Recollecting the past in the present to engineer a better future}

After Libor, the emphasis was on 'turning the chapter' and to embark on a process of organisational renewal to restore 'pride, reputations and generate more positive personal identities'. According to the shared accounts the FXG values programme had been well embedded in working 
practices and individual behaviours even if it 'would take some years to really see the benefit of it'.

"We've been the face of a lot of what has been seen to be bad and gone wrong. I think we should be equally the face of the change and this is how the industry should be. And I think ultimately that will play out well, if we get it right." Managing director, Wealth

Reinforcing the cultural changes in everyday social interaction between employees was a major factor in trying to maintain the impetus for change, supported by leaders who role-modelled the new values and sought regular feedback on progress. Any evidence of expressed attitudes about the past e.g. talking about 'the numbers', were denounced by advocates of the values. This was most obvious from the reconstructed memories of employees in the retail bank. Indeed, behavioural compliance (Ogbonna \& Harris, 2001) to the new values framework was most evident in the retail bank as employees were in direct contact with customers. Employees recalled a drastic shift in discourse which reinforced their belief that change in 'past unethical behaviours' was required:

"Directly before the recession I remember our bosses proudly telling us that we were widget sales people. That's what we were paid to do....go away and sell more widgets....within three years or certainly where we are now, I know this isn't true, but it almost feels like our bosses, my bosses don't care if I sell anything or not. All they care about is the relationship that I have with our clients. Now I know that is not true, but it feels as extreme as that. It's a complete mind-change...if I acted now, the way I do now, five years ago or six years ago, I would probably be managed out of the business.". Branch manager, retail bank.

Yet in other areas of the bank, challenges to embed the new values in new behaviours started to appear. For instance a shared recollection was the problems generated by lack of continuity in the leadership team (particularly in Wealth) where the average tenure among managing directors was two years. The psychologically-safe environment that had been created in the retail bank where long-tenured members were able to use the past to create meaning in the present was lacking in other sub-groups where the environment was more fluid:

"Every time someone comes in new they start from zero. Literally zero. And so you have to build up all that knowledge all over again... and it just means that you never make any 
progress in reality. You always go back to the beginning....having continuity allows, you know...there's more solid virtues because people are going to be in a job for a long time and want to look after it. That's why stewardship comes in...you don't just get told to be a steward and then it sort of happens...you're a steward because you care enough" Vice President, Wealth

In summary, breaking with the past was viewed positively by the vast majority of employees as it enabled them to put a 'shameful past' (Olick, 1997) behind them and imagine a better future. There were shared memories of a genuine desire to both restore reputations and support FXG's vision to change the face of banking. In this sense, employees felt part of a wider social movement which facilitated change receptiveness. Yet the immediate responses to the cultural change programme that ensued in the wake of 'turning the page' were strikingly different. At the extremes, employee reactions ranged from outright resistance where the very notion of imposing a culture was considered offensive to complete acceptance where employees became akin to the 'Orwellian mindpolice' (Ogbonna \& Harris, 1998) for denouncing colleagues who were not operating within the new values framework. These two different recollections of the past are explored in the rest of this section. We have focused on three distinct recollections in relation to leadership, ethical behaviours and working practices as they had a direct impact on the way employees' position themselves regarding the cultural change program.

\subsubsection{Leadership}

Particular recollections of the past were used by FXG employees as a way to position themselves as members of certain groups and/or as defending a certain vision of the FXG history. For instance, the appointment of a British Group CEO in July 2012 was generally remembered as a key point in the process of change. His nationality symbolized for many FXG employees a break from the recent past - the American 'go-go years of mega bonuses' (Pratley, 2013) and risk-taking. Yet, for the employees on the retail bank his appointment was a reconnection, a way of taking the organisation back to its familial roots. Contrary to the emphasis on 'the need to break with the past' 
emphasized by public internal and external campaigns; hiring a 'British' CEO was seen as purposeful in legitimising a 'back to the future' reinvention of the bank and enabled employees to re-identify with their 'original' organisation (Press \& Arnould, 2011) challenging while 'complying' with wider societal influences.

"It is a very British institution, ridiculously, given the sort of cultural inputs we've had from senior leadership...just in the general persona of the organisation, if you can have one, it is still very British... and I can say this as a British person, as I know I have some of the same traits about being reserved, and you know, not wanting to sort of rah rah - being front-offoot and cheerleading" Managing Director, Wealth

For employees in the retail bank, the ascent of their former leader symbolised continuity amid disconfirmation which facilitated an enormous amount of good-will for him. Unsurprisingly the retail bank employees became the staunchest supporters of the cultural change program through this 'back to the past through change' episode that could make their future a continuity of their past.

Employees in the investment bank and Wealth, while also nostalgic for the past reframed the hiring of a British CEO quite differently. In their case the recollections took the form of a narrative about the end of the Golden 'American past' where they talked about the loss of their charismatic, American leader who had built the investment bank from scratch into a well-respected global organisation. Their recollections of this 'golden past' were interwoven with references to their own past and current identity and status. They expressed themselves as proud to have been a part of his legacy and were offended by the management team attempts to engineer a new culture when organisational wrong-doing was linked to a minority of people. They saw the new culture as devoid of meaning and their imagined future as 'number one' in danger.

"In the [former CEO] era, there was a culture and everyone was in it together and we were going to be number one bank in Europe and then we were going to be number one in the globe...that's where we were going and this is what we were going to be and people believed it...you just knew. So it was just different... and this culture now, I don't like...because there isn't a culture. They tell us there's one, they think if they keep telling us 
there's one, there will be one. There won't. And this is why people are leaving". Director, investment bank

\subsubsection{Ethical behaviours}

Every participant interviewed insisted they had always behaved and that the new values framework simply codified how they had been operating historically. They were not aware of colleagues acting unethically either - such behaviour was viewed as isolated incidents within the bank. Yet, many employees while stating they did not see the need to 'mend their ways' (Munro, 2001) supported a change in culture. For instance a regional manager of retail stated early in the interview:

"For me, it's not been real cultural change. If I was still a [FX Group] business manager, I'd still be the same person but just with a different way of doing a one-to-one document." Regional manager, retail bank

Later on in the interview however, unquestioning support for the cultural change programme was espoused, hoping for a better future and especially when recollecting incidents that demonstrated that perhaps the past was 'not all good' after all:

"[FX Group] isn't gonna change....that's what it stands for now...I can't ever, ever see us going back there and I wouldn't want it to go back there if I'm honest. I think we're doing the right thing now."

Investment bank employees felt that being 'told' how to behave was insulting and missed the point. People behave with decency because they care about what they do, not because they are told to. The new mantra about putting the customer 'front and centre' was perceived as farcical because employees would lose business if this had not always been the case. They saw banking as a commoditised business and 'you live and die on your reputation':

"If I tell a customer to $\mathrm{f}^{* * *}$ off, he will go and use any one of ten or fifteen brokers around the street because my business is commoditised...so what differentiates me is my service. So therefore, I'm kind of living a set of values anyway. ...if I don't do what I'm asked, if I do the complete opposite of what I'm asked, any of those things, they're gonna just go "your line is out, I'm gone". And they'll pick up the line to Deutsche or Citibank or Morgan 
Stanley or Credit Suisse" Director, Investment bank.

\subsubsection{New Working practices}

Further attempts to 'break with the past' were in the form of discarding 'material manifestations' (Ogbonna \& Harris, 1998) across the organisation such as league tables, performance appraisal documents and incentive schemes. These systems were portrayed as representing the past that needed to be forgotten - e.g. the aggressive focus on sales over service and shareholders over customers. An example that was frequently recalled was the change in sales strategy and performance appraisals and their impact on working practices and incentives for both retail and investment bank employees. Many employees welcomed the change recalling the 'sales strategy' and the subsequent performance appraisals as too aggressive and unbalanced:

"If you hadn't introduced an interest rate swap you were basically held up as a swap virgin. You were almost ridiculed....there was still quite a lot of peer group pressure going on...We were pretending to meet the customers' needs, but actually it would be quite convenient if our customers' needs met our own needs...You're targeted on it, so you're making damn sure they take it. And I was uncomfortable with that....it was all about selling, you know, and that continued really until our current chief executive took over and put in our [change] programme. And that's when the culture changed." Senior manager, retail bank

Other employees -using the same example- remembered the old performance appraisals as 'more balanced' since the new performance appraisal document had been re-designed to focus on values and behaviours rather than sales. In fact sales targets had been removed from the document altogether. This process intensified work for managers and their staff as reviews could now take up to 'two hours' per person and that was excluding preparatory time beforehand. Employees were required to explain in granular detail how their behaviour was aligned to the values rather than describe what they had achieved. Increased control over work processes (McCabe, 2010) and transparency meant that 'no-one could hide' and served as an argument to resist the cultural change program. Thus, the past working practices were recalled by different groups as both too aggressive 
-in Retail- as well as 'better balanced' - in Wealth and Investment-.

Furthermore, employees in wealth and investment bank especially remembered that FXG had been through cultural change programmes in the distant past and that the new values framework was a reconstruction of what had gone on before. Questions were raised about the longevity of the new programme if FXG suffered financially, prompting a return to old ways of working. Cynicism resulted in a generic resistance to any kind change. There were many shared stories relating to the separation between management rhetoric and organisational reality (Vaara, 2003) and those stories were recalled as the greatest barrier to change. An example of the many recollections of poor behaviour by management circulating on the grapevine is the following:

"What kind of future treatment you want? There is still no respect for individual staff...the branch manager at [X branch] left two weeks ago after 35 years of service and got not even a single phone call... from his boss to say goodbye and thank you" Branch manager, Wealth bank

Senior management regarded them however as 'urban myths'. Even in the retail bank, were the staunchest supporters for change were; the new culture was being led by the same regional and senior management teams, some of whom had actively encouraged their staff to 'misbehave' in the past.

\subsubsection{The uncertain future}

The emphasis on change generated pressures for all the bank's groups. Each sub-group was experiencing high levels of stress and multiple changes taking place at once (Bartunek, 2006). The retail bank was feeling the impact of digitalisation in the form of redundancies, branch closures and changes to working patterns as a result of a changing banking landscape. The investment bank was facing an uncertain future and Wealth was in a 'liquid environment' where episodes of mass redundancies, re-structuring, high turnover among senior leaders and cost-cutting had severely dampened morale and motivation to support additional changes. The future was uncertain for all. 
This resulted in an uneven experience of cultural change between and within sub-groups which created 'change fatigue' and inhibited receptiveness to the programme (McCabe, 2010).

Furthermore, FXG was seen ultimately a bank answerable to its shareholders. For most employees regardless their support or rejection of the cultural change program meeting the demands of the City and society were perceived to be dichotomous rather than complementary strategies. According to the shared accounts, the organisation was at a cross-road and needed to decide 'who it wanted to be' (Gioia, Schultz \& Corley, 2000):

"I think the approach we're taking is one of humility, which is a reasonable path, but I query that if that is the path, that it will lead in its end game to being one of the survivors when there are other firms that are more confidently taking the challenges in their strides. Not questioning...just simply the acceptability of capitalism almost. The acceptability of making money from the transaction... that is the question." Managing Director, investment bank

It is clear that the narratives FXG share are important social tools in forming a temporal account of how individuals are situated and develop within particular socio-cultural worlds in organizations (Brown, 2006; Ybema, 2014). These narratives enable the process of remembering at FXG. Remembering becomes then a socially constructed practice that transmits meaning and identities from the historical past of the organization through stories and narratives but also shapes future expectations. Conceptualizing organizational memory as a dynamic process is part of a larger oeuvre in organizational and management literature that aims to understand individuals in context (Rowlinson et al, 2014).

\section{Discussion}

In this paper we have explored how the collective recollection of episodic events such as two well publicized financial scandals involving the FX Group (FXG) impacted the receptiveness to and engagement with a cultural change programme among its employees. We show how the past was 
brought differently into the present by different organizational groups depending on the future each group imagined, counteracting the impact of a generic management narrative. Our findings illustrate the collective, emotional and imaginative qualities of organizational remembering and provide new insights into the process of cultural change through the lens of memory showing how while some memories may be shaped by management to respond to crisis, they can also be part of a diverse transformative and prospective process.

Current research in organizational memory shows how collective memories constructed in the present (Olick \& Robbins, 1998) by organizational actors are shaped and maintained by cultural products, such as narratives, that sustain a particular version of the past (Mena et al., 2016). However, the recollections of impactful events are not isolated individual stories but narratives that reflect certain groups' perspectives framing how and what is remembered (Halbwachs, 1992; Middleton \& Brown, 2005). Thus, as our analysis has shown, individual employees in FXG position their recollections of the financial scandals in the perspective of the organizational group they identify themselves with or as part of defending a certain vision of the FXG history. For instance, retail bank employees framed the appointment of a new British CEO as a way of taking the organisation back to its familial secure British roots, away from the risk taking past behaviours of the previous American CEO. On the other hand, investment bank employees framed the new appointment as a loss of their 'golden past' and grieved for their previous charismatic, American leader. The way recollections occurred showed how those memories were socially anchored on each group current needs and goals, including the defence of a positive group identity. The evocation of the FXG recent past became a process of memory making that adapted and justified past events to the groups' values and attitudes of the present. A consequence of those varied recollections was the diversity in support for the proposed cultural change program: while many of the retail bank employees supported it, it was rejected as unnecessary by employees at the investment bank 
(Carroll, 2002). The recollection of the past across FXG was therefore not a homogeneous, curated and consensual process but rather a contested polyphonic process (Foroughi, 2019; Smith \& Russell, 2016) where multiple voices contributed to weave the fabric of FXG's organizational memories.

Studying collective memories as a polyphonic process offers new insights in the making, shaping and change of group memories in organizations (Smith \& Russell, 2016). A polyphonic approach enables us to study the alternative memory narratives emerging in line with particular group identities in FXG, complementing and/or challenging the official renditions of the past financial scandals. While it is clear that many employees from Wealth and the retail bank supported the management narrative and its drive for cultural change, investment bank employees felt that being 'told' how to behave was insulting and missed the point. Investment bank employees also challenged new 'mantras' such as putting the customer 'front and centre' recollecting that they have always done so to keep the business going. Thus, the recollection of episodic memories at FXG was not only shaped by the rhetorical work of a small number of actors such as the managers (Basque $\&$ Langley, 2018) but also by other employees' interpretations and challenges to the main narrative over time. While management guided recollections can frame a desired organizational identity to drive cultural change through explicit 'identity claims' (Anteby \& Mulnar, 2012) such as the 'proud' history of FXG, the process of remembering and its impact on organizational change processes needs to be studied from the perspective of all organizational actors. Our research supports therefore previous studies that look into the importance of groups for the production of collective memories going beyond the focus on stories only told by management to offer a more complex picture of collective memories in organizations (Adorisio, 2014; Foroughi, 2019; Ybema, 2014) .

We can also see in our analysis the emotional effects of collective remembering by means of 
social sharing. FXG employees' shared accounts recall external pressure after the scandal and the doubts it provoked as the catalyst for change and the 'will-to-cleanse' by the management team at FXG. This metaphor neatly describes the process of cutting out unethical practices and behaviours as part of an inclusion/exclusion principle (Cooper, 1986, p. 331) leaving what is 'right and appropriate' on the inside. As a result of this pressure, a new values-led organisational culture was engineered top down and disseminated through 'The FXG story' to provide a framework for 'good' behaviour at all levels in the organisation and restore trust with customers. In this context, particular recollections of the organization's 'moral failure' and the associated emotions played a critical role in the shaping of what was seen as the need for a new 'moral culture' (Feldman and Feldman, 2006, p. 879). Rather than perceiving emotions as barriers or by products of change that need to be controlled, they were actively used to provoke reflection, change (Bartunek, 2006) and 'selfregulation' (Creed et al, 2014) to comply with the new order.

A particularly strong emotion was the general 'felt shame' (Creed et al, 2014) as response to the media campaign. This emotional reaction was galvanised to motivate change. This finding supports recent research on the 'shame nexus' - a set of shame-related constructs in organizations: felt shame, systemic shame, sense of shame and episodic shaming (Creed et al; 2014). The strong media campaign referred as the 'Bonfire of the bankers' can be seen as episodic shaming; a form of 'judicial power' (p. 280) where institutions such as the mass media deploy 'shaming attempts' to provoke change when the behaviour of another community or organisation(s) is perceived to be unethical. As research in psychology shows, the action tendency related to shame is wanting to hide or conceal actions, but can also leads to self-improvement and to restoring identity (Lewis, 1993). The recollections of unethical behaviour were used by both media and FXG management to facilitate receptiveness to change (Weick et al, 2005, p. 416) during the launch of the cultural change programme. Furthermore, strategic decisions to sell off highly profitable but unethical 
business operations were publicized to send a bold message to all stakeholders that FXG was serious about fundamental reform. Thus, critical events such as the financial scandals FXG was involved in provoke strong shared emotions such as surprise, sadness and shame particularly when the organization becomes the target of sustained emotionally charged recounts.

A third key finding in our analysis is the prospective function of organizational remembering. It is clear in our analysis that the ways in which different groups remember the past have implications for how they act in the present (Bartlett, 1956; Halbwachs, 1992). But we have also seen how different groups in the organization use the future too. Organizational memory research has rarely explored how the past shapes the prefiguration of the future in organizational actors recollections of episodic events. In our analysis we have seen how there are different emergent visions of FXG future, reflecting the tensions between current reality and possible futures among various groups in the organization. For the investment bank employees, negative recollections of the organization's past risk the 'number one' market position future they imagine for the bank while the retail bank employees imagine returning to an 'honourable' past. The prospective function of memory - its ability to help us imagine what may come (Dudai \& Carruthers 2005) - become clear in FXG's narratives bringing together past, present and future in anticipation of future organizational needs. Retail bankers foresee the need to retain and regain clients while investment bank employees state the need to be competitive. Remembering and imagining are intertwined processes present in the FXG employees' recollections. This view of remembering is influential in conceptualizing how and why organizational actors imagine both the past and future, and the impact of what is imagined on their actions in the present. Thus, prefiguring the future entails a strong engagement with retrospective remembering.

The different groups in FXG focused on creating acceptable, believable, pragmatic versions of memory more than on a 'truthful' collective memory, and therefore on developing usable 
memories of the past financial scandals rather than truthful ones. It can be argued that the diversity of these acceptable, believable, pragmatic, accounts testifies to an active interrelationship between memory and imagination. While past events gave meaning to the present FXG situation for its employees; anticipating the future gave them significance, by allowing imagination of what may or may not matter down the line and work towards prevent it happening (Glăveanu 2018). We know that organizational memories that are articulated out of living with a difficult and sometimes contested past (Gabriel 2012) should not be seen simply as truthful accounts but instead involving imaginative reconstructions in terms of what is being recollected and its significance for ongoing identification with self and others (Anteby \& Mulnar, 2012). Imagination and memory are therefore intertwined resources for making sense of organizational experiences as "imagination is vital in reactivating memory, and memory is vital in stimulating imagination” (Keightley \& Pickering, 2012 p. 51). Keightley and Pickering use the notion of 'mnemonic imagination' to refer to the relationship between remembering that "draws upon certain symbolic resources ... and is in itself intrinsic to cultural processes of one kind or another" (p. 82), and imagination through which we develop a sense of the temporal relations between different experiences, different episodes and different stages in our lives. A key role of imaginative organizational reconstructions therefore is to symbolically align past, present and future, and create a sense of collective continuity.

While our findings challenge the assumption that organizational memories could be managed top down to produce desired employees' identities and/or cultural values (Alvesson \& Willmott, 2002); recent research suggests that change management programmes can however silence certain memories while supporting the circulation of others (Martin de Holan \& Phillips, 2004; Foroughi \& Al-Amoudi, 2019). It is important therefore to understand how curated historical recollections may be challenged by different organizational actors using their memories and their imagination in different ways. Alternative imaginative recollections can provide the conditions for 
real transformative action in the present, oriented towards desired futures.

\section{Conclusions}

By bringing the past into the present, organizational memory processes can serve as a powerful resource to provide meaning, contexts and belonging in diverse organizational contexts. In this research we propose to look at organizational remembering as a process that engages with memories of the past not only as evocation to reproduce traditions but also as possibilities to be actualized or rejected in the present in view of future aspirations.

Our research contributes to expand our understanding of organizational remembering by illustrating how remembering in organizations is indeed a collective process where multiple voices contribute to weave organizational memories. A polyphonic approach to study collective remembering enables us to give voice to particular organizational groups, complementing and/or challenging official narratives. Imagination, as does memory, points in different directions, serves different functions, and operates beyond concerns with desired or even truthfulness of perspectives. A clear contribution of our research is to empirically show the link between past and future or remembering and imagination. In the FXG employees recollections past, present, and future are put in circular dialogue by individuals and groups in the organization.

Furthermore, as we have seen in our research, remembering groups in the organization engage in imaginative reconstructions in order to produce relevant collective stories. Their diverse reconstructions challenge the imperative of 'shared organizational memories' to 'integrate' and 'calibrate' different perspectives and stances on the past so present in organizational memory research. Thus, in current research the sharing of organizational memories means, primarily, the attempt to integrate and calibrate of what is not yet worked-through, including ambivalent and suppressed memories and meanings. It also means the integration and calibration of a mnemonic 
imagination that can envisage alternative possible collective futures. We propose to give more weight to the imaginative reconstructions of troubled and contested past events as they can enable individuals, as well as groups and organizations, to "turn around" and to "reshuffle constituent elements" (Keightley \& Pickering, 2012, p. 57) of the past to reposition themselves more positively within the circular narrative of past, present and future.

\section{Bibliography}

Ackerman, M.S. (1998). Augmenting organizational memory: A field study of Answer Garden. ACM Transactions on Information Systems, 16: 203-224

Adorisio, A. L. M. (2014). Organizational remembering as narrative:'Storying’ the past in banking. Organization, 21(4), 463-476.

Akgun, A.E., \& Keskin, H. (2012). The role of organizational emotional memory on declarative and procedural memory and firm innovativeness. Journal of Product Innovation Management (Vol. 29, pp. 432-451).

Albert, S., \& Whetten, D. (1985). Organizational identity. In L.L., Cummings \& B.M. Staw (Eds.), Research in Organizational Behavior, vol. 7: 263-295. Greenwich, CT:JAI Press

Alavi, M., Kayworth, T. R., \& Leidner, D. E. (2005). An empirical examination of the influence of organizational culture on knowledge management practices. Journal of management information systems, 22(3), 191-224.

Alvesson, M., \& Willmott, H. (2002). Identity regulation as organizational control: Producing the appropriate individual. Journal of management studies, 39(5), 619-644.

Anteby, M., \& Molnár, V. (2012). Collective Memory Meets Organizational Identity: Remembering to Forget in a Firm's Rhetorical History. Academy of Management journal, 55(3), 515-540.

Argyris, C. \& Schon, D. A. (1978). Organizational learning. Reading, MA: Addison Wesley Publishing Company.

Bartunek, J. M. (2006). On the Receiving End: Sensemaking, Emotion, and Assessments of an Organizational Change Initiated by Others. The Journal of Applied Behavioral Science, 42(2), 182-206. doi: 10.1177/0021886305285455

Bate, P. (1995). Strategies for cultural change. Oxford [England]: Routledge.

Bartlett, F.C. (1956). Remembering. Cambridge: Cambridge University Press.

Berthon, P., Pitt, L.A., \& Ewing, M.T. (2001). Corollaries of the collective: The influence of organizational culture and memory development on perceived decision-making context. Journal of the Academy of Marketing Science, (2), 135-150.

Boje D. M. (1991). Consulting and change in the story telling organisation. Journal of Organisational change management Vol.4,3, 7-17.

Boyatzis, R. (1998). Transforming qualitative information: thematic analysis and code 
development. Thousand Oaks, CA: Sage Publications.

Braun, V. \& Clarke, V. (2006). Using thematic analysis in psychology. Qualitative Research in Psychology, 3(2): 77-101.

Brown, A.D.(2006). A narrative approach to collective identities. Journal of Management Studies, 43:731-753

Carnelley, K. B., \& Janoff-Bulman, R. (1992). Optimism about love relationships: General vs specific lessons from one's personal experiences. Journal of Social and Personal Relationships, 9(1), 5-20.

Carroll, C. E. (2002). The strategic use of the past and future in organizational change Introduction. Journal of Organizational Change Management, 15(6), 556-562.

Casey, A. J., \& Olivera, F. (2011). Reflections on organizational memory and forgetting. Journal of Management Inquiry, 20(3), 305-310.

Cooper, R. (1986). Organization/Disorganization. Social Science Information, 25(2): 299-335

Creed, D.W.E., Hudson, B.A., Okhuysen, G.A., \& Smith-Crowe, K. (2014) Swimming in a sea of shame: incorporating emotion into explanations of institutional reproduction and change. Academy Management Review, Vol. 39, No3, 275-301.

Davies, H. (2010). The financial crisis: who is to blame. London: Polity.

Dudai, Y., \& Carruthers, M. (2005). Memory: some systems in the brain may be better equipped to handle the future than the past. Nature, 434, 567.

Einwiller, S., \& Korn, C. (2013). Media coverage about organisations in critical situations: analysing the impact on employees. Corporate communications, 18(4), 451-468.

Feldman, S. P., \& Feldman, R. M. (2006). What Links the Chain: An Essay on Organizational Remembering as Practice. Organization, 13(6), 861-887.

Fereday, J., \& Muir-Cochrane, E. (2006). Demonstrating rigor using thematic analysis: A hybrid approach of inductive and deductive coding and theme development. International Journal of Qualitative Methods, 5(1): 80-92.

Flick, U. (1998). An introduction to qualitative research. London, UK: Sage Publications.

Foroughi, H. (2019). Collective Memories as a Vehicle of Fantasy and Identification: Founding stories retold. Organization Studies, 0170840619844286.

Foroughi, H., \& Al-Amoudi, I. (2019). Collective Forgetting in a Changing Organization: When memories become unusable and uprooted. Organization Studies, 0170840619830130.

Fridenson, P. (2008). Business history and history. In: Jones, G., and Zeitlin, J. (2008). The Oxford handbook of business history. Oxford University Press. pp, 9-36.

Gabriel, Y. (2012). Organizations in a state of darkness: Towards a theory of organizational miasma. Organization studies, 33(9), 1137-1152.

Garcia-Lorenzo, L. (2010). Framing uncertainty: narratives, change and digital technologies. Social 
science information, 49(3), 329-350.

George, J. M., \& Jones, G. R. (2001). Towards a process model of individual change in organizations. Human Relations, 54, 419-444.

Gersick, C. J. (1991). Revolutionary change theories: A multilevel exploration of the punctuated equilibrium paradigm. Academy of management review, 16(1), 10-36.

Gilbert, D. T., \& Wilson, T. D. (2007). Prospection: Experiencing the future. Science, 317(5843), 1351-1354.

Gioia, D. A., Schultz, M., \& Corley, K. G. (2000). Organizational identity, image, and adaptive instability. Academy of management Review, 25(1), 63-81.

Gioia, D. A., Corley, K. G., \& Hamilton, A. L. (2013). Seeking qualitative rigour in inductive research: Notes on the Gioia methodology. Organizational research methods, 16(1), 15-31.

Glăveanu, V. P. (2018). Educating which creativity?. Thinking Skills and Creativity, 27, 25-32.

Halbwachs, M. (1925/1992). On collective memory. Edited, translated and with an introduction by Coser, L.A. Chicago: University of Chicago Press.

Hernes, T. (2014). A process theory of organization. OUP Oxford.

Holland, J. (2010). Banks, knowledge and crisis: A case of knowledge and learning failure. Journal of Financial Regulation and Compliance, (2), 87-105.

House of Lords (2013) Parliamentary Commission on Banking Standards: Changing Banking for Good. [online] [cited June 2013] Retrieved from: http://www.parliament.co.uk

Hobsbawm, E., \& Ranger, T. (1983). The Invention of Tradition. Cambridge: Cambridge University Press.

Martin de Holan, P. M. D., \& Phillips, N. (2004). Remembrance of things past? The dynamics of organizational forgetting. Management science, 50(11), 1603-1613.

Humphreys, M., \& Brown, A. D. (2002). Narratives of organizational identity and identification: A case study of hegemony and resistance. Organization Studies, 23(3), 421-447.

Keightley, E., \& Pickering, M. (2012). The mnemonic imagination. Palgrave Macmillan, London.

Kotter, J. (1996). Leading change. Boston, Mass.: Harvard Business School Press.

Korn, C., \& Einwiller, S.(2013). Media coverage about organisations in critical situations:

Analysing the impact on employees. Corporate Communications: An International Journal, (4), 451-468.

Kuhn, T, \& Corman, S. R. (2003). The emergence of homogeneity and heterogeneity in knowledge structures during a planned organizational change. Communication Monographs, 70, 198229

Lewin, K. (1951/1997). Problems of research in social psychology. In D. Cartwright (Ed.). Field theory in social science: Selected theoretical papers (pp. 155-169). NewYork, NY: Harper \& Row. 
Lewis, M. (1993). Self-conscious emotions: embarrassment, pride, shame and guilt. In M. Lewis and J. M. Haviland (Eds.) Handbook of emotions .Pp. 563-573. New York: The Guilford Press.

Martin, J. (2002). Organizational Culture: Mapping the Terrain. London: Sage

McCabe, D. (2010). Taking the long view: a cultural analysis of memory as resisting and facilitating organizational change. Journal of Organizational Change Management, 23(3), 230-250

Mena, S., Rintamäki, J., Fleming, P., \& Spicer, A. (2016). On the forgetting of corporate irresponsibility. Academy of Management Review, 41(4), 720-738.

Moorman, C., \& Miner, A. S. (1998). Organizational improvisation and organizational memory. Academy of management Review, 23(4), 698-723.

Munro, R. (2001). Unmanaging/Disorganisation. www.ephemeraweb.org. Volume 1 (4): 395-403.

Ogbonna, E., \& Harris, L. C. (1998). Managing organizational culture: compliance or genuine change?. British Journal of Management, 9(4), 273-288.

Nag, R., \& Gioia, D.A (2012). From common to uncommon knowledge: Foundations of firmspecific use of knowledge as a resource. Academy of Management Journal, (2), 421-457.

Nwachukwu, S. L., \& Vitell Jr, S. J. (1997). The influence of corporate culture on managerial ethical judgments. Journal of Business Ethics, 16(8), 757-776.

Olick, J.K., \& Levy, D. (2007). The politics of regret: On collective memory and historical responsibility. London: Routledge

Olick, J. K., Vinitzky-Seroussi, V., \& Levy, D. (2011). The collective memory reader. Oxford University Press.

Parker, M. (2000). Organizational culture and identity: Unity and division at work. Sage.

Peston, R (2013, April 3) 'FX Group’s Salz Review blames bank culture'. Retrieved from www.bbc.co.uk

Pratley, N (2013, March 11) [senior investment banker's] Fat Cat in the Hat makes it hard for FX Group's' message to stick. The Guardian. Retrieved from http://theguardian.com

Press, M., \& Arnould, E. J. (2011). How does organizational identification form?: A consumer behaviour perspective. Journal of Consumer Research, 38(4), 650-666.

Parliamentary Commission on Banking Standards (2013). Changing Banking for Good.

Ravasi, D., \& Schultz, M. (2006). Responding to organizational identity threats: Exploring the role of organizational culture. Academy of Management Journal, 49(3), 433-458.

Ricoeur, P. (2004). Memory, history, forgetting. University of Chicago Press.

Risberg, A., Tienari, J., \& Vaara, E. (2003). Making sense of a transnational merger: media texts and the (re) construction of power relations. Culture and Organization, 9(2), 121-137. 
Rowlinson, M. (2010). Social Remembering and Organizational Memory. Organization Studies, $31(1), 69-87$.

Rowlinson, M., Hassard, J., \& Decker, S. (2014). Research strategies for organizational history: A dialogue between historical theory and organization theory. Academy of Management Review, 39(3), 250-274.

Salz, A. (2013) An independent Review of FX Group's' business practices. Retrieved from https://online.wsj.com/public/resources/documents/Salzreview

Seligman, M. E., Railton, P., Baumeister, R. F., \& Sripada, C. (2013). Navigating into the future or driven by the past. Perspectives on Psychological Science, 8(2), 119-141.

Schachter, D.L. (2001). The seven sins of memory: the brain, the mind and the past. New York: Basic Books

Schein, E. H. (1993). How can organizations learn faster? The challenge of entering the green room. Sloan Management Review, 34(2), 85-92.

Schein, E. H. (1996). Kurt Lewin's change theory in the field and in the classroom: Notes toward a model of managed learning. SYSTEMS PRACTICE, 9(1), 27-47.

Shotter, J. (1990). The Social Construction of Remembering and Forgetting, D. Middleton and D. Edwards (eds) Collective Remembering, p. 120-37. London: Sage

Schultz, M., Hatch, M. J., \& Larsen, M. H. (Eds.). (2000). The Expressive Organization: Linking Identity, Reputation, and the Corporate Brand: Linking Identity, Reputation, and the Corporate Brand. Oxford University Press.

Schultz.M., \& Hernes,T. (2013). A temporal perspective on organizational identity. Organization Science, (1), 1-21

Schuman, H., \& Scott, J. (1989). Generations and collective memories. American sociological review, 359-381.

Schwartz, B. (2003). Abraham Lincoln and the Forge of National Memory. Chicago, IL: University of Chicago Press.

Silverman, R (2013, August 8) Bank of England governor calls for change in banks' culture. The Telegraph. Retrieved from http://telegraphy.co.uk

Smith, R (2013 March 11) 'FX Group's [senior investment banker] in Cheltenham festival 'insult' with his racehorse fatcatinthehat'. Retrieved from http://www.mirror.co.uk

Smith, A., \& Russell, J. (2016). Toward polyphonic constitutive historicism: a new research agenda for management historians. Management \& Organizational History, 11(2), 236-251.

Sørensen, J. B. (2002). The strength of corporate culture and the reliability of firm performance. Administrative science quarterly, 47(1), 70-91.

Starbuck, W. H. (2017). Organizational learning and unlearning. The Learning Organization, 24(1), 30-38.

Stein, E. W. (1995). Organization memory: Review of concepts and recommendations for 
management. International Journal of Information Management, 15(1), 17-32.

Stewart, H \& Treanor, J (2012, December 23) Banking industry's year of shame ends in a blizzard of Libor revelations. The Guardian. Retrieved from http://theguardian.com

Türcke, C. (2015) Schrecken, Schuld und Schlachtopfer: Eine kleine Geschichte des Geldes (Horror, guilt and sacrifice. A short history of money). Retrived from: http://www.nzz.ch/feuilleton/schrecken-schuld-und-schlachtopfer-1.18501543

Turner (2009) The Turner Review: A regulatory response to the global banking crisis. Retrieved from http://www.fsa.gov.uk

Vaara, E. (2003). Post-acquisition Integration as Sensemaking: Glimpses of Ambiguity, Confusion, Hypocrisy, and Politicization. Journal of Management Studies, 40(4), 859-894.

Vinitzky-Seroussi, V., \& Teeger, C. (2010). Unpacking the unspoken: Silence in collective memory and forgetting. Social Forces, 88(3), 1103-1122.

Vygotsky, L. S. (2004). Imagination and creativity in childhood. Journal of Russian \& East European Psychology, 42(1), 7-97.

Walsh, J. P., \& Ungson, G. R. (1991). Organizational Memory. The Academy of Management Review, 16(1), 57-91.

Weick, K. E., Sutcliffe, K. M., \& Obstfeld, D. (2005). Organizing and the process of sensemaking. Organization science, 16(4), 409-421.

Wertsch, J. V. (1997). Narrative tools of history and identity. Culture \& Psychology, 3(1), 5-20.

Wertsch, J. V. (2009). Collective remembering. SEMIOTICA, 173(1-4), 233-247

Ybema, S. (2014). The invention of transitions: History as a symbolic site for discursive struggles over organizational change. Organization, 21(4), 495-513. 
Table 1: The collective remembering of financial events at FXG

\begin{tabular}{|c|c|c|c|}
\hline \multicolumn{4}{|c|}{ Collective memory Processes at FXG } \\
\hline $\begin{array}{l}\text { Evocation: } \\
\text { The triggers } \\
\text { for reflection } \\
\text { and cultural } \\
\text { change }\end{array}$ & \multicolumn{3}{|c|}{$\begin{array}{l}\text { - } \quad \text { Financial crisis 2008: "It was not us". } \\
\text { - } 2012 \text { and } 2013 \text { Financial Scandals: "We need to re-set". } \\
\text { - } \quad \text { Bonfire of the Bankers: } \\
\text { O Banker bashing: Not all bankers are the same. } \\
\text { O Personal attacks on FX Group: We were never given a fair trial. }\end{array}$} \\
\hline \multirow{7}{*}{$\begin{array}{l}\text { Memory } \\
\text { making: } \\
\text { Recollecting } \\
\text { the past in the } \\
\text { present to } \\
\text { engineer a } \\
\text { better future }\end{array}$} & COMMON THEMES & RECOLLECTIONS BY & DIFFERENT GROUPS \\
\hline & & Retail bank & Wealth and Investment Bank \\
\hline & $\begin{array}{l}\text { 'Turning the chapter' to } \\
\text { restore Group's } \\
\text { reputation: Reasons for } \\
\text { needing new cultural values } \\
\text { in FXG. }\end{array}$ & $\begin{array}{l}\text { Bad reputation due to past } \\
\text { unprofessional and ethical } \\
\text { behaviours. } \\
\text { Examples of resulting behaviours: } \\
\text { 'Denouncing' colleagues not } \\
\text { operating within the New Values } \\
\text { Framework (NVF). }\end{array}$ & $\begin{array}{l}\text { Bad reputation due to lack of } \\
\text { continuity in Leadership. } \\
\text { Examples of resulting behaviours: } \\
\text { Resistance to NVF. 'Imposing' a new } \\
\text { culture is 'offensive'. }\end{array}$ \\
\hline & $\begin{array}{l}\text { Leadership. Appointment } \\
\text { of new British CEO. }\end{array}$ & $\begin{array}{l}\text { Back to 'honourable' past through } \\
\text { change. } \\
\text { Examples of resulting behaviours: } \\
\text { Staunch support for new British } \\
\text { CEO. }\end{array}$ & $\begin{array}{l}\text { The end of the Golden 'American } \\
\text { past'. } \\
\text { Examples of resulting behaviours: } \\
\text { Resistance to management changes. } \\
\text { NVF seen as a threat to personal } \\
\text { Identity and 'number one' market } \\
\text { position. }\end{array}$ \\
\hline & $\begin{array}{l}\text { Ethical behaviours: } \\
\text { Need to improve ethically } \\
\text { and put the customer at the } \\
\text { centre. }\end{array}$ & $\begin{array}{l}\text { We need to mend our ways. } \\
\text { Examples of resulting behaviours: } \\
\text { Support for required cultural change } \\
\text { to 'do the right thing'. }\end{array}$ & $\begin{array}{l}\text { We always behaved ethically. } \\
\text { Examples of resulting behaviours: } \\
\text { Rejection of new cultural values as } \\
\text { 'insulting' and offensive. }\end{array}$ \\
\hline & $\begin{array}{l}\text { New working practices: } \\
\text { Discarding 'material } \\
\text { manifestations' (e.g. } \\
\text { performance appraisals) to } \\
\text { 'break with the past'. }\end{array}$ & $\begin{array}{l}\text { Past performance appraisals' 'too } \\
\text { aggressive' focus on sales outputs. } \\
\text { Examples of resulting behaviours: } \\
\text { Explicit Support for the more values } \\
\text { and behaviours focused performance } \\
\text { appraisals. }\end{array}$ & $\begin{array}{l}\text { Past performance appraisals 'better } \\
\text { balanced'. } \\
\text { Examples of resulting behaviours: } \\
\text { Cynicism and generic resistance to } \\
\text { new changes in working practices. }\end{array}$ \\
\hline & $\begin{array}{l}\text { The uncertain future: } \\
\text { High levels of stress and } \\
\text { multiple changes taking } \\
\text { place at once. }\end{array}$ & $\begin{array}{l}\text { Need to regain honourable past to } \\
\text { retain and regain clients. }\end{array}$ & $\begin{array}{l}\text { Need to regain key market position } \\
\text { lost after the scandals. }\end{array}$ \\
\hline
\end{tabular}

